\title{
Effect of loT on Marketing Intelligence and Business Strategy: An Organizational Capability Perspective
}

\author{
Wei-Hsiu Weng \\ National Chengchi University \\ Department of Management Information Systems \\ wilsonw.weng@msa.hinet.net
}

\begin{abstract}
Innovative developments in the Internet of Things (IoT) have invoked tremendous attention from both academics and industries. Studies suggest that IoT not only serves as an innovative tool for enterprise operations but also triggers impacts on business performance. As researchers increasingly raise issues about the business value of IoT, this study examines its direct and indirect managerial effects by investigating the link between IoT and business strategy. From the organizational capability perspective, this study constructed a research framework in which marketing intelligence capability mediates the effect of IoT capability on business strategy formation. This research performed an empirical survey and analyzed the data to test the hypotheses in the research framework. The results confirmed the partial mediating effect of marketing intelligence capability in the link between IoT capability and business strategy formation. The paper then discussed the test results and elaborated on the managerial implications.
\end{abstract}

Keywords: Internet of Things, marketing intelligence, business strategy, organizational capability

\section{INTRODUCTION}

Many organizations consider the evolution of the Internet of Things (IoT) as "the next big thing" of information technology [1, 2]. Firm managers expect the development of various IoT related technologies to affect enterprises' managerial paradigm and business strategy. IoT attracted attention as a possible source of strategic advantage for firms [3]. It may provide business opportunities for companies, and may even change the future market [4]. Therefore, aligning with the development of IoT has become critical for the formulation and execution of a firm's business strategy.

The perceived capability of IoT implies that firms make strategic decisions more efficiently. By employing IoT, firms should be able to recognize new business opportunities, identify possible threats, and maintain competitiveness. However, studies of the relationship between IoT and business strategy are rare in the literature so far. To fill this gap, this study intends to investigate the link between IoT and business strategy. 
In order to use IoT, a firm needs to integrate IoT with the functional operations. Therefore, the functional operations influence the link between IoT and business strategy. Among the functional operations, this research focuses on marketing for several reasons. First, marketing strategy plays a crucial role in shaping the overall business strategy of a firm $[5,6]$. Second, marketing is tightly related to many other functional operations of a firm, such as production, sales, and customer service [7-12]. Finally, IoT enabled products and services are transforming marketing paradigm $[3,13$, 14].

Furthermore, in a firm's marketing operations, marketing intelligence is the foundation of overall marketing activities, because marketing decisions rely on the capability of acquiring and interpreting accurate marketing intelligence [15]. Therefore, the objective of this research is to investigate the linkages among IoT, business strategy, and marketing intelligence.

The paper begins with a review of the relevant literature about the relationships between the Internet of Things, marketing intelligence, and business strategy. Then it proposes a model that links these three variables. Following that, the paper describes the procedure that tests the model using a sample of Taiwanese companies with global operations. Finally, the paper presents the findings along with managerial implications, research limitations, and recommendations for future work. An earlier version of this paper has been presented at the $20^{\text {th }}$ International Conference on Electronic Business.

\section{LITERATURE REVIEW AND HYPOTHESES DEVELOPMENT}

\subsection{Internet of Things}

The Internet of Things is an integration of various information and communication technologies [1, 2, 16-21]. Among its major features, ubiquitous sensing is the mechanism that the "things" or devices in IoT perceive the surrounding physical environment, detect and record the changes in the environment, and respond to the changes $[22,23]$. Ubiquitous sensing is enabled by wireless sensor network (WSN) technologies [1, 17, 18, 24]. The data detected and collected by sensor networks are transmitted through pervasive connectivity networking [24, 25]. IoT contains multiple layers of communication networking infrastructure to provide the pervasive communications between people and people, people and things, and things and things, to form a smart environment $[16,17,26]$. Data in IoT systems are processed through embedded computing functionality. IoT devices contain embedded hardware and software to work intelligently within the environment. The embedded hardware includes processor chips, data storage units, and power units. The embedded software includes embedded operating systems, mobile apps, and middleware. In particular, IoT devices can be embedded further in other devices [17, 19, 27]. IoT monitored and detected information is invisibly embedded in the environment around users, results in the generation of big data in real-time, which is distributed, stored, processed, presented, and interpreted in a seamless, efficient, and easily understandable form [17, 19, 28]. Cloud support is provided by IoT systems for processing the real-time analytics. IoT systems deploy cloud services to assist the processing and storage of IoT analytics, and provide IoT users ubiquitous access to supporting services initiated by IoT devices around the smart environment [16-18, 29]. Users of the IoT-enabled smart environment are supported with interactive user interface. Visualizing, touching, and listening are 
critical for an IoT application as these functions allow the IoT users to be aware of the IoT environment. 3D viewing and printing technologies, personal mobile assistants, wearable devices, and augmented-reality systems provide a novel interface for users to interact with the smart environment $[17,18,30]$. Integrating the IoT with the recent development of the blockchain technology is the next major challenge to expand the applications of the IoT [31-34].

In addition to IoT-enabled environments, IoT technologies are commercialized by embedding IoT components in various interconnected smart products. IoT enables the evolution of various products such as smart home appliances, robots, drones, crewless cars, automated factory machines and business equipment, and many other innovative devices [2, 19, 21, 26, 27]. The smart environments and interconnected smart products can further enable cyber-physical convergence. The convergence of computer network, telecom network, and IoT triggers further convergence of cyberspace and physical space, and results in various smart spaces, such as smart home, smart office, smart factory, smart laboratory, smart store, smart marketplace, smart hospital, smart museum, and smart city $[2,17,18,20]$.

From the business aspect, IoT capability refers to the firms' ability to integrate resources and skills arising from IoT to align with the firms' strategic directions [35, 36]. However, up to now, few studies have examined the capabilities needed to adopt IoT in an organization and how these capabilities relate to different types of business strategy, particularly from the perspective of an innovative and market-oriented organization. Therefore, to contribute with a required research framework of IoT and business strategy, this study examines the role of IoT capability further in business strategy formation.

\subsection{Internet of Things and Business Strategy}

From the strategic management perspective, cost leadership and differentiation are two essential approaches to competitive advantage and basic choices of business strategy [37, 38]. Furthermore, researchers have argued that cost leadership and differentiation are not mutually exclusive, but rather are compatible approaches to dealing with external situations, and a combination of strategies could lead to success in various circumstances [39-41]. In the IoT context, whether a firm wants to achieve cost advantage, differentiation advantage, or a combination of both through its IoT capability is a strategic intent, which causes the firm to formulate and implement IoT facilitated cost leadership strategy, differentiation strategy, or a combination of both types of strategy.

Cost leadership strategy requires organizational capabilities to achieve operational efficiency, including time efficiency, cost efficiency, and flexibility. The problem is that employees have spare time and imperfect accuracy, and therefore, they are not very good at capturing information about things in the physical world. The IoT sensor technology enables connected devices to sense, observe, and understand the physical world - without the limitations of human entered data [42]. Furthermore, enterprises will be flexible enough to respond to production changes swiftly with IoT capability. The functions of IoT-enabled smart factory can integrate technologies of many disciplines. IoT capability helps an enterprise to make extensive use of artificial intelligence, simulation, automation, robotics, sensors, data collection systems, and networks towards advanced engineering and precision machining. These systems make 
possible the establishment of efficient, collaborative, and sustainable industrial production to achieve cost leadership [43].

Differentiation strategy requires organizational capabilities to achieve product or service uniqueness for higher customer premiums. Firms realize products or services differentiation through innovation or customization. IoT capability provides higher accuracy on analyzing and identifying distinctive customer preferences through hidden analytics of interconnected products. Sensor-based information collected through IoT embedded products covers actions of customer purchase and use, and can be analyzed to obtain a much more precise and complete picture of the customer's characteristics and preferences [44]. Smart laboratories can provide test fields for innovative products and services before delivery to customers. Customer feedbacks are collected and transmitted in real-time through various sensor networks and supportive cloud services for further refinement of innovation or customization. Thus IoT capability could expand opportunities for product or service differentiation, moving competition away from cost alone.

Therefore, this study proposes the following two hypotheses:

H1a. IoT capability is positively associated with cost leadership strategy formation.

H1b. IoT capability is positively associated with differentiation strategy formation.

\subsection{Internet of Things and Marketing Intelligence}

IoT capability can enhance marketing intelligence capability because IoT capability enables a firm with a better ability to sense and collect information from customers and competitors [45]. Taylor, Reilly and Wren [46] examined how the IoT can provide communication channels to support marketing and enhance customer relationship management and product support. Pavlou [47] argued that IoT augmented intelligence has the potential to address some of the emerging business challenges than pure artificial intelligence in the foreseeable future. Shin [48] proposed collaboration among companies for sharing information on environmental changes and sensing market needs as an innovation path for IoT value chain. Guarda and Augusto [49] discussed using the IoT as a digital ecosystem to address geographic market intelligence for greater effectiveness in marketing campaigns. Wu, Chen and Dou [50] discovered that smart interaction and brand positioning provided by the IoT have interaction effects on brand attachment. The case study of Lo and Campos [51] showed that the application of IoT solutions positively affects the process of developing long and successful relationships through relationship marketing actions. However, so far the direct relationship between IoT capability and marketing intelligence capability has not been studied.

IoT capability indicates the ability to merge the digital world with the world of things. It involves the ability of convergence of the manufacturing systems with the power of cloud computing, big data analytics, pervasive sensing, and internet connectivity [20]. For a firm with IoT capability, large scale real-time customer surveys can be conducted with the assistance of sensing and recognition technology. Augmented reality enhanced user interface allows users to view and test products and services using their smartphones, tablets, or 3D viewing glasses. The big data from IoT connected products provide a clear picture of product use, showing the features customers prefer. By comparing usage patterns, firms can identify more precise market 
segmentation information [21]. Firms can then apply this knowledge to generate more valuable intelligence and develop more sophisticated pricing strategies that better match price and value at the market segment.

As such, IoT capability can enhance a firm's marketing intelligence acquisition efforts, representing the extent to which they can generate and disseminate marketing intelligence, and which may lead to novel interpretations and recombination of prompt responses to marketing situations. Thus with IoT capability, a firm can transform marketing intelligence capability and enhance marketing results. In summary, we propose the following hypotheses:

H2. IoT capability is positively associated with marketing intelligence capability.

\subsection{Marketing Intelligence and Business Strategy}

Business strategy formation includes mission and goal clarity, situation analysis, comprehensiveness of alternative evaluation, and strategy formation process [52]. A business strategy concerns the competitive positioning, market segmentation, and industry environment of a company [37]. To survive, grow, and sustain, a firm needs to monitor its internal and external status for possible changes. Thus the formulation and execution of a business strategy rely heavily on the collection, extraction, analysis, interpretation, and prediction of internal and external status data of the company [53, 54]. Therefore, a firm's marketing intelligence capability is critical in facilitating its business strategy formation. Business strategies of most companies are frequently a combination of their intended strategies and the emergent strategies [55]. Business leaders need to analyze the status information of emergence and to make strategy adjustments when appropriate [56]. For this purpose, marketing intelligence capability is also essential as the ability for the strategic decisions to be accurately updated and aligned with competition changes $[57,58]$.

Marketing intelligence capability enables a firm to acquire and analyze the cost structures and distinctive features of products and services of peers in the marketplace. It helps the firm to determine which market segments are suitable for cost leadership, and which market segments are feasible for differentiation. Marketing intelligence about cost analytics of all levels needs to be collected and accurately analyzed for a firm to maintain a viable leading cost status. Marketing intelligence regarding customer preferences and distinctive features are required for a firm to determine the need to differentiate its products against the need to keep its cost structure under control in order to offer a unique product at a competitive price [52,59].

Therefore, the author proposes the following two hypotheses:

H3a. Marketing intelligence capability is positively associated with cost leadership strategy formation.

$\mathrm{H} 3 \mathrm{~b}$. Marketing intelligence capability is positively associated with differentiation strategy formation.

Based on our proposed hypotheses, we illustrate the research framework in Figure 1. 


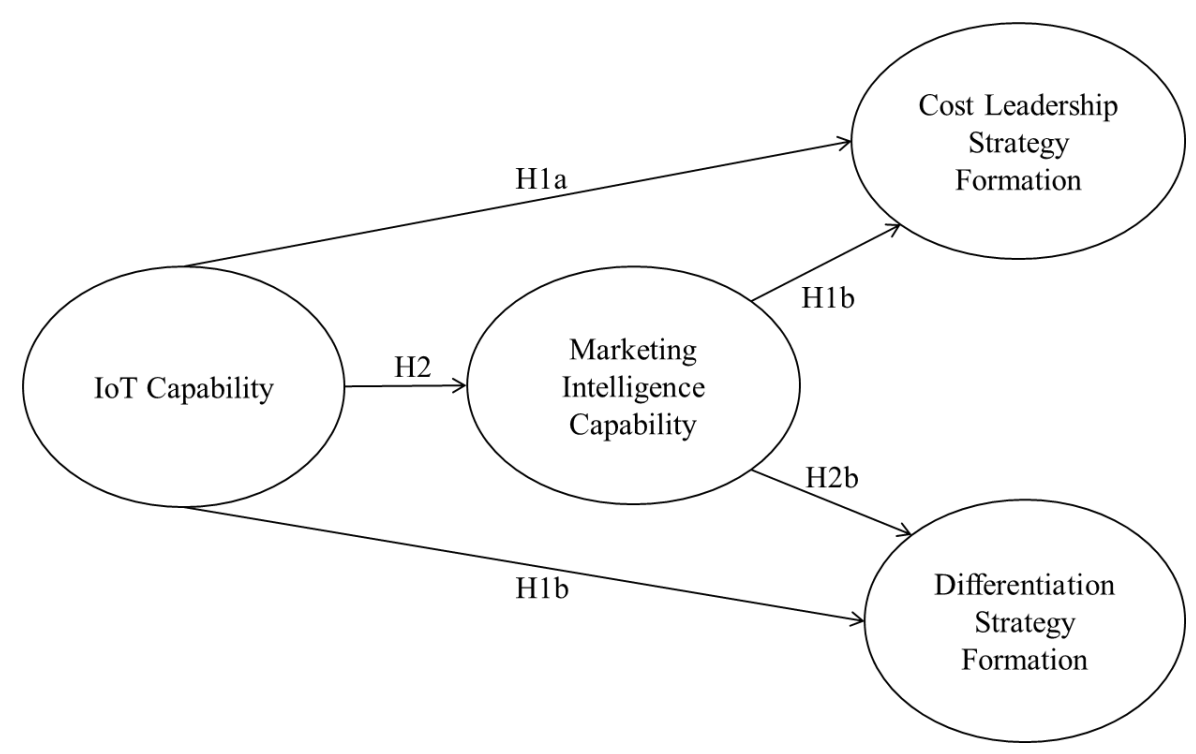

Figure 1. Research framework

\section{RESEARCH METHOD}

\subsection{Survey Instrument}

The survey instrument uses questions derived from the literature on information technology capabilities, marketing capabilities, and Porter's typology of competitive strategies discussed previously. We operationalized the study variables by using multiitem reflective measures on a 7-point scale [60] in Table 1.

Following the definition of information technology capability by Bharadwaj [35], a firm's IoT capability is measured here by its ability to develop or deploy IoT based resources, which include the tangible IoT resources, the intangible IoT resources, and the human IoT resources. The tangible IoT resources are tangible things such as IoT components, IoT connected products, and IoT enabled smart environments (IoT1). The intangible IoT resources are assets such as knowledge, know-how, and synergy about IoT (IoT2). The human IoT resources comprise technical and managerial IoT staffs (IoT3). Thus we measure the core capability arising from IoT with three items based on these three types of IoT resources. Also, these three items are the source to the IT capability proposed by [61]: IoT infrastructure capability (IoT1), IoT proactive stance (IoT2), and IoT business spanning capability (IoT3).

A firm's marketing intelligence capability concerns its competency in intelligence generation, intelligence dissemination, and responsiveness [62, 63]. Marketing intelligence capability is operationalized as the accessibility and utilization of resources and activities within a firm to collect and analyze market information and utilize it to develop effective marketing programs. The ability to effectively gather and disseminate customer and competitor information is critical for marketing intelligence capability $[63,64]$. This four-item scale was from Vorhies, Morgan and Autry [65] and Trainor, Krush and Agnihotri [15].

The construct of cost leadership strategy formation was measured using four items that reflect the extent to which a firm forms a cost-oriented strategy. The formation of a cost leadership strategy aims at achieving low manufacturing and distribution costs $[37,64,66]$. The third item was the economic scale. A firm can usually lower costs 
through economies of scale or superior manufacturing processes [37, 67]. Finally, the formation of cost leadership often reflects a lower price of products or services $[66,68]$. The construct of differentiation strategy formation was measured using four items that reflect the extent to which a firm forms a differentiation strategy. Differentiation implies being unique or distinct from competitors by providing superior functionality or customized feature within products or services to customers [37,69]. Extending Porter's business strategy framework, Miller [70] discriminated differentiation strategy based on innovation from that based on intensive marketing [70, 71]. This distinction forms two items included in the construct.

All items for this study adopted a 7-point Likert scale ranging from "strongly disagree" to "strongly agree." Furthermore, firm size, IT department size, and industry sector were used as control variables, as these variables have been noted in several studies to affect the deployment of information technologies [72, 73]. Table 1 presents the items used to measure each of the independent and dependent construct variables.

Table 1. Constructs and items used in the survey

Construct and item description ( 1 - strongly disagree; 7 - strongly agree)

\section{IoT: Internet of Things capability}

IoT1: Our company is competent in developing or deploying IoT technologies such as IoT components, IoT connected products, or IoT enabled environments.

IoT2: We possess sophisticated IoT knowledge, intelligence, and synergy.

IoT3: Our employees are proficient in IoT technologies and related business applications.

\section{MIC: Marketing intelligence capability}

MIC1: Our company is competent in collecting information about customers and competitors

MIC2: We are proficient in tracking customer needs and wants

MIC3: We are skillful in analyzing and disseminating marketing information

MIC4: We are competent in developing effective marketing programs

\section{CLS: Cost leadership strategy formation}

CLS1: We provide low-cost products or services based on manufacturing efficiency

CLS2: Our products or services have a lower distribution cost than our competitors

CLS3: We develop and deliver products or services with an economy of scale

CLS4: Our products or services have lower prices than competitors in the market

\section{DFS: Differentiation strategy formation}

DFS1: We deliver products or services with superior functionality to our competitors

DFS2: We provide products or services with a customized feature to our customers

DFS3: Our firm differentiates our products or services based on innovation

DFS4: Our firm differentiates our products or services based on intensive marketing

\section{Control Variables (rescaled)}

Industry: Industry sectors of firms.

Firm Size: Total number of employees.

IT Size: Total numbers of IT staffs. 


\subsection{Sample and Data Collection}

Enterprises operating in Taiwan were surveyed in order to test the hypotheses. A questionnaire designed following Table 1 above was implemented as the survey instrument. It was then pretested with 13 business executives and managers. The pretesting focused on instrument clarity, wording, and validity. Members of the pretesting sample were invited to comment on the questions and wording of the questionnaire. The comments of these respondents then provided a basis for revisions to the questionnaire to establish content validity.

A sample of 1,000 firms was randomly selected from the top 5,000 list of the largest companies in Taiwan published by a Taiwanese market research organization. Most of the companies on the list are public listed corporations with international operations. In the questionnaire we asked for top MIS managers or CIO level to answer our survey questions. The survey, which took three months to complete, was initially conducted by postal mail and e-mail, and then followed up with telephone calls and inperson visits. A total of 217 responses were received, of which 16 were unusable and eliminated. The remaining 201 responses were used in this study, for a response rate of $20.1 \%$.

Table 2. Profile of the final sampling firms

\begin{tabular}{lcc}
\hline & Sample size & Percentage \\
\hline Industry & 99 & \\
Manufacturing & 102 & 59.3 \\
Services & 201 & 50.7 \\
Total & & 100.0 \\
Firm size & 53 & \\
Under 100 & 52 & 26.4 \\
100-199 & 38 & 25.9 \\
$200-499$ & 58 & 18.9 \\
500 and above & 201 & 28.9 \\
Total & & 100.0 \\
IT department size & 83 & \\
Under 5 & 54 & 41.3 \\
$5-19$ & 64 & 26.9 \\
20 and above & 201 & 31.8 \\
Total & & 100.0 \\
\hline
\end{tabular}

The mean differences between responding and non-responding firms were compared along with firm attributes using t-tests, and all statistics were non-significant $(p>0.5)$. Furthermore, the responses were classified into two groups to examine whether there was any response bias. The responses received during the first two months were classified as early returns, and those received during the last months as of late returns. The two groups were then compared for any significant difference in responses using the chi-square test of independence. No significant difference was 
found between these two groups, supporting that response bias is not an issue in this study [74]. Table 2 lists the profile of the final sample.

\section{RESULTS}

Partial least square structural equation modeling (PLS-SEM) was performed using SmartPLS package for hypothesis testing [75]. Figure 2 exhibits the PLS-SEM model based on Figure 1.

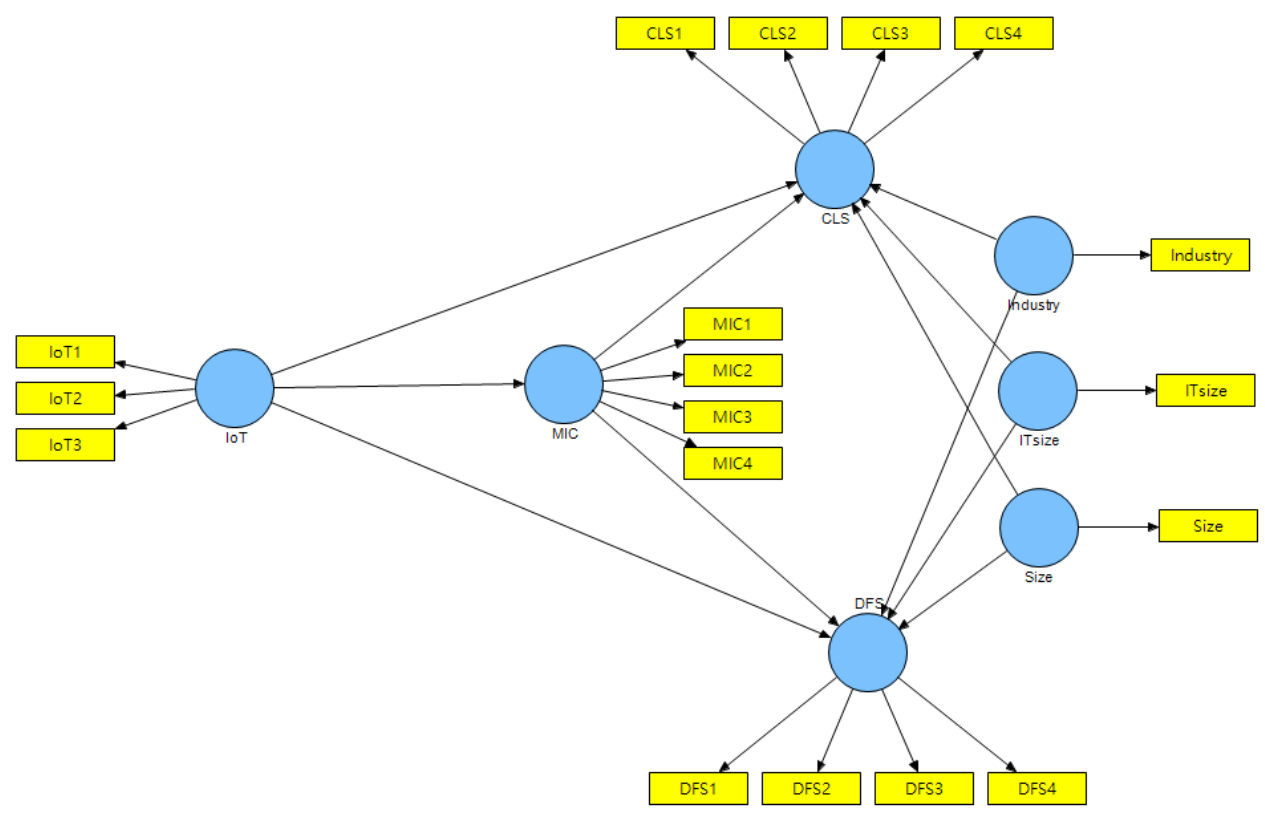

Figure 2. PLS-SEM model

\subsection{Reliability and Validity}

Table 3 summarizes the descriptive statistics and results of the reliability and validity tests. The reliability of the instrument was examined using composite reliability estimates by employing Cronbach's $\alpha$. All the coefficients exceeded Nunnally's recommended level $(0.70)$ of internal consistency [76, 77]. Also, factor analysis was performed to confirm the construct validity. The results supported the constructs of our research model. The discriminant validity was confirmed since items for each construct loaded on to single factors with all loadings higher than 0.8 . These results confirmed that each of the constructs in our hypothesized model is unidimensional and factorially distinct and that all items used to operationalize a construct is loaded onto a single factor.

Table 4 summarizes the correlations among different factors. We also assessed discriminant validity based on the construct correlation that Campbell and Fiske [78] proposed. The values in the diagonal are the square root of AVE (average variance extracted), which should exceed the inter-construct correlations for adequate discriminant validity. The tests indicated acceptable results concerning discriminant validity. 
Table 3. Descriptive statistics and reliability and validity test

\begin{tabular}{ccccccc}
\hline Construct & Item & Mean & SD & $\begin{array}{c}\text { Cronbach's } \\
\text { alpha }\end{array}$ & $\begin{array}{c}\text { Cronbach's alpha } \\
\text { if item deleted }\end{array}$ & $\begin{array}{c}\text { Factor loading } \\
\text { on single factor }\end{array}$ \\
\hline IoT & IoT1 & 4.114 & 1.712 & 0.805 & 0.745 & 0.841 \\
& IoT2 & 3.622 & 1.642 & & 0.719 & 0.857 \\
& IoT3 & 4.776 & 1.695 & & 0.736 & 0.847 \\
MIC & MIC1 & 4.672 & 1.201 & 0.880 & 0.844 & 0.866 \\
\hline \multirow{2}{*}{ Construct } & Item & Mean & SD & $\begin{array}{c}\text { Cronbach's } \\
\text { alpha }\end{array}$ & $\begin{array}{c}\text { Cronbach's alpha } \\
\text { if item deleted }\end{array}$ & $\begin{array}{c}\text { Factor loading } \\
\text { on single factor }\end{array}$ \\
& MIC2 & 4.697 & 1.115 & & 0.830 & 0.888 \\
& MIC3 & 4.731 & 1.130 & & 0.836 & 0.879 \\
& MIC4 & 4.532 & 1.196 & & 0.876 & 0.804 \\
& CLS1 & 4.343 & 0.847 & 0.855 & 0.779 & 0.885 \\
& CLS2 & 4.383 & 0.979 & & 0.810 & 0.827 \\
& CLS3 & 4.129 & 0.850 & & 0.837 & 0.783 \\
& CLS4 & 4.597 & 1.105 & & 0.809 & 0.843 \\
& DFS1 & 4.637 & 1.050 & 0.852 & 0.828 & 0.801 \\
& DFS2 & 4.542 & 1.277 & & 0.800 & 0.849 \\
& DFS3 & 4.512 & 1.196 & & 0.796 & 0.853 \\
& DFS4 & 4.701 & 1.136 & & 0.815 & 0.824 \\
\hline
\end{tabular}

Table 4. Construct correlation

\begin{tabular}{|c|c|c|c|c|c|c|c|}
\hline Construct & 1 & 2 & 3 & 4 & 5 & 6 & 7 \\
\hline 1. IoT & 0.848 & & & & & & \\
\hline 2. MIC & 0.336 & 0.859 & & & & & \\
\hline 3. CLS & 0.368 & 0.659 & 0.834 & & & & \\
\hline 4. DFS & 0.371 & 0.668 & 0.621 & 0.831 & & & \\
\hline 5. Firm Size & 0.112 & 0.021 & 0.063 & 0.036 & 1.000 & & \\
\hline 6. IT Size & 0.063 & -0.067 & 0.017 & -0.026 & 0.400 & 1.000 & \\
\hline 7. Industry & 0.041 & -0.121 & -0.034 & -0.043 & -0.083 & -0.242 & 1.000 \\
\hline
\end{tabular}

\subsection{Tests of Hypotheses}

The computation result of the model using partial least square algorithm is shown in Figure 3. Table 5 lists the quality indicators of the PLS model.

The AVE (average variance extracted) values of the four variables are all above 0.50 , indicating the acceptable explanation powers of the four latent variables towards their measuring items [79]. The composite reliability are all above 0.7 . The values of $\mathrm{R}^{2}$ of the three endogenous latent variables show medium predictability. The VIF (variance inflation factor) values of IoT and MIC are both less than 5.0, indicating low collinearity between the two variables [79]. 
Table 5. Quality indicators of the PLS model

\begin{tabular}{ccccc}
\hline Variable & AVE & Composite Reliability & R Square & VIF \\
\hline IoT & 0.719 & 0.884 & & 1.159 \\
\hline MIC & 0.738 & 0.918 & 0.113 & 1.172 \\
\hline CLS & 0.695 & 0.901 & 0.463 & \\
\hline DFS & 0.690 & 0.899 & 0.471 &
\end{tabular}

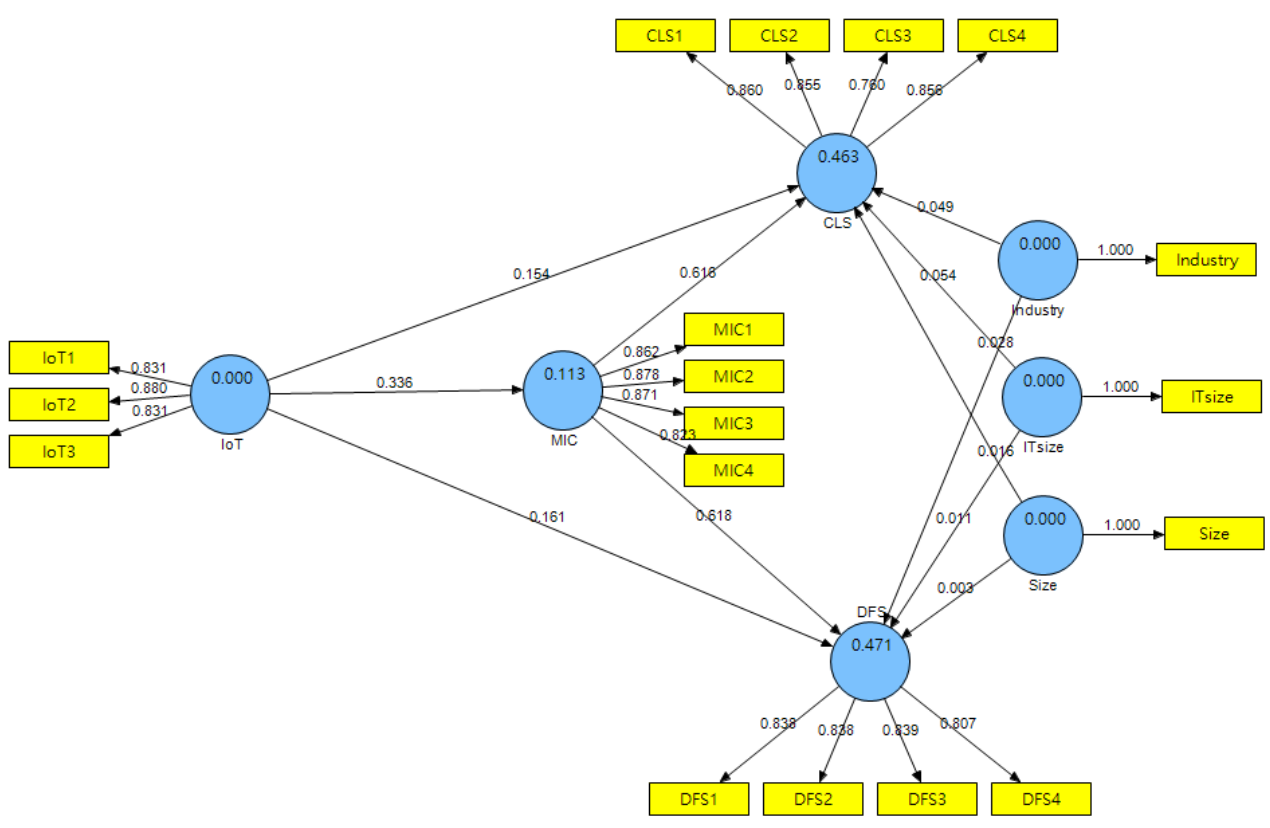

Figure 3. PLS-SEM computation result

Table 6 shows the significance test results of the path coefficients in the PLS model using bootstrapping. All of the path coefficients in the PLS model are tested significant.

Table 6 Significance tests of path coefficients

\begin{tabular}{cccc}
\hline Path & Path coefficient & t value & p value \\
\hline IoT $->$ CLS & 0.154 & 2.508 & $0.013^{*}$ \\
\hline IoT $>$ DFS & 0.161 & 2.688 & $0.008^{* *}$ \\
\hline IoT $>$ MIC & 0.336 & 4.519 & $0.000^{* * *}$ \\
\hline Path & Path coefficient & t value & p value \\
\hline MIC $->$ CLS & 0.616 & 9.859 & $0.000^{* * *}$ \\
\hline MIC $->$ DFS & 0.618 & 9.373 & $0.000^{* * *}$ \\
\hline
\end{tabular}

$* \mathrm{p}<0.05, * * \mathrm{p}<0.01, * * * \mathrm{p}<0.001$

Table 7 shows the significance test results of the partial effects in the PLS model using bootstrapping. The VAF (variance accounted for) values for the two indirect effects in Table 8 are between 0.2 and 0.8 , which verify the partial effects of MIC in 
the two links $[79,80]$. The causal effects of paths in Figure 1 are summarized in Table 8 .

Table 7. Significance tests of effects

\begin{tabular}{cccccc}
\hline Path & Effect type & Effect & t value & p value & VAF \\
\hline IoT $>$ CLS & Total effect & 0.361 & 4.767 & $0.000^{* * *}$ & \\
\hline IoT $->$ DFS & Total effect & 0.368 & 5.352 & $0.000^{* * *}$ & \\
\hline IoT $>$ > CLS & Effect without MIC & 0.397 & 6.087 & $0.000^{* * *}$ & \\
\hline IoT $->$ DFS & Effect without MIC & 0.378 & 5.444 & $0.000^{* * *}$ & \\
\hline IoT $>$ - MIC $>$ CLS & Indirect effect & 0.207 & 4.453 & $0.000^{* * *}$ & 0.573 \\
\hline IoT $>$ - MIC $->$ DFS & Indirect effect & 0.207 & 4.411 & $0.000^{* * *}$ & 0.563 \\
\hline
\end{tabular}

${ }^{*} \mathrm{p}<0.05,{ }^{* *} \mathrm{p}<0.01,{ }^{* * *} \mathrm{p}<0.001$

Table 8. Causal effects of paths in the hypothesized model

\begin{tabular}{ccc}
\hline Hypothesis & Path & The causal effect from test results \\
\hline H1a & IoT $\rightarrow$ CLS & $\begin{array}{c}\text { Direct effect supported } \\
\text { Partial mediation of MIC supported }\end{array}$ \\
\hline H1b & IoT $\rightarrow$ DFS & $\begin{array}{c}\text { Direct effect supported } \\
\text { Partial mediation of MIC supported }\end{array}$ \\
\hline H2 & IoT $\rightarrow$ MIC & Direct effect supported \\
\hline H3a & MIC $\rightarrow$ CLS & Direct effect supported \\
\hline H3b & MIC $\rightarrow$ DFS & Direct effect supported \\
\hline
\end{tabular}

\section{DISCUSSION}

\subsection{Research Implications}

This study investigated the impact of a firm's IoT capability on business strategy formation and tested the possible mediating role of marketing intelligence capability. By supporting the research hypotheses, this study can help business managers and strategy practitioners realize the links between organizational capabilities and business strategy formation.

First, our results support the positive correlations between two different organizational capabilities and the formation of two types of business strategies. The findings demonstrate that both IoT capability and marketing intelligence capability can have positive effects on the formation of both cost leadership strategy and differentiation strategy, which could further lead to competitive advantage [37, 67]. Therefore, the study serves to inform business managers that firms should do more than just invest in innovative technologies or marketing operations. They need to identify and build distinctive capabilities and put them in productive use. This study suggests that both IoT capability and marketing intelligence capability are worthy of attention in 
this regard. The findings that these capabilities may impact business strategy formation indicate that their influence on a firm are cross-functional and may transcend managerial hierarchy.

Second, this study identifies a mediator in the association between IoT and business strategy. While IoT capability influences business strategy formation positively, our findings also point out that the link between IoT capability and business strategy formation is partially mediated by marketing intelligence capability. Our study is unique in that it explores the link between IoT capability and marketing intelligence capability. Our findings support not only the marketing orientation concept of Jaworski and Kohli [81], but also the hierarchy model of capabilities of Grant [36]. From the managerial implication perspective, the marketing department in a firm is skillful at sensing and understanding the outside environment. If a business strategy of a firm can fit into its surroundings, its performance is usually enhanced. Thus, a marketing department in a firm becomes critical for a firm to make its business strategies fit with its surroundings. Our findings suggest that IoT capability can facilitate the marketing department of a firm for the generation, dissemination, and analysis of marketing intelligence to shape the firm's business strategy for competitive advantage.

Finally, our findings indicate the similar effects of organizational capabilities on the two types of business strategies. Both cost leadership strategy formation and differentiation strategy formation are positively influenced by IoT capability and marketing intelligence capability. This finding demonstrates that both IoT capability and marketing intelligence capability can enhance business strategy formation, regardless of the strategy typology. In essence, IoT capability and its output, pervasive sensing and connectivity with embedded analytics, enable firms to deploy and operate in smart environments and thus could enhance the functional level operations with efficiency and flexibility to achieve cost leadership or differentiation, or a combination of both. It is also because of the cross-functional nature of pervasive sensing and connectivity with embedded analytics, IoT capability can have a positive influence on some other organizational capabilities, such as marketing intelligence capability. Marketing intelligence capability and its output, marketing intelligence, enable firms to anticipate and understand better the customer needs and the competitive situation, to deal with this information faster, and to develop products and services with lower cost or with differentiated features, which empower firms to sustain a competitive advantage.

\subsection{Study Limitations and Further Research}

Although this study reported meaningful implications regarding the development of multidimensional measures of constructs in our hypothesized framework, it should be realized that the validity of an instrument cannot be firmly established based on a single study. In this study, all data used for tests were collected from firms based in Taiwan. Therefore, practitioners and academics are suggested to interpret our findings as a reference model rather than generalizing our measures to the different research contexts.

Further research efforts that focus on accumulating more empirical evidence for assessing and validating empirical data are recommended to overcome the limitations of the present study. Such research is required to address how other emerging technologies are related to business strategies and functional operations. For example, wearable interface technology [30, 82-84] and augmented reality technology [85-87] have received inadequate attention from strategic considerations and organizational 
capability theories. Also, special attention could be focused on data collected in various sub-industries or specific contexts over an extended period. The analysis of these data may enable conclusions to be drawn about more generalized relationships among business-level strategy, functional-level strategy, and technology-based organizational capability.

\section{REFERENCES}

[1] E. Borgia, "The internet of things vision: key features, applications and open issues," Computer Communications, Vol. 54, pp. 1-31, 2014.

[2] D. Miorandi, S. Sicari, F. De Pellegrini, and I. Chlamtac, "Internet of things: Vision, applications and research challenges," Ad Hoc Networks, Vol. 10, No. 7, pp. 1497-1516, 2012.

[3] M. E. Porter, and J. E. Heppelmann, "How smart, connected products are transforming competition," Harvard Business Review, Vol. 92, No. 11, pp. 64-88, November, 2014.

[4] M. Iansiti, and K. R. Lakhani, "Digital ubiquity - how connections, sensors, and data are revolutionizing business," Harvard Business Review, Vol. November, pp. 91-99, November, 2014.

[5] C. B. Dobni, and G. Luffman, "Determining the scope and impact of market orientation profiles on strategy implementation and performance," Strategic management journal, Vol. 24, No. 6, pp. 577-585, 2003.

[6] G. S. Day, and R. Wensley, "Marketing theory with a strategic orientation," Journal of Marketing, Vol. 47, No. 4, pp. 79-89, 1983.

[7] P. Guenzi, and G. Troilo, "Developing marketing capabilities for customer value creation through Marketing-Sales integration," Industrial Marketing Management, Vol. 35, No. 8, pp. 974-988, 2006/11/01/, 2006.

[8] D. Rouziès, and J. Hulland, "Does marketing and sales integration always pay off? Evidence from a social capital perspective," Journal of the Academy of Marketing Science, Vol. 42, No. 5, pp. 511-527, September 01, 2014.

[9] Y. Wang, and H. Feng, "Customer relationship management capabilities," Management Decision, Vol. 50, No. 1, pp. 115-129, 2012.

[10] S.-M. Tseng, "Knowledge management capability, customer relationship management, and service quality," Journal of Enterprise Information Management, Vol. 29, No. 2, pp. 202-221, 2016.

[11] A. Respício, and M. E. Captivo, "Marketing-production interface through an integrated DSS,” Journal of Decision Systems, Vol. 17, No. 1, pp. 119-132, 2008.

[12] W. Chang, J. E. Park, and S. Chaiy, "How does CRM technology transform into organizational performance? A mediating role of marketing capability," Journal of Business Research, Vol. 63, No. 8, pp. 849-855, 2010/08/01/, 2010. 
[13] E. d. S. Zancul, S. M. Takey, A. P. B. Barquet, L. H. Kuwabara, P. A. Cauchick Miguel, and H. Rozenfeld, "Business process support for IoT based productservice systems (PSS)," Business Process Management Journal, Vol. 22, No. 2, pp. 305-323, 2016, 2016.

[14] M. Bulearca, and D. Tamarjan, "Augmented reality: a sustainable marketing tool?," Global Business and Management Research, Vol. 2, No. 2/3, pp. 237-252, 2010, 2010.

[15] K. J. Trainor, M. T. Krush, and R. Agnihotri, "Effects of relational proclivity and marketing intelligence on new product development," Marketing Intelligence \& Planning, Vol. 31, No. 7, pp. 788-806, 2013, 2013.

[16] L. Atzori, A. Iera, and G. Morabito, "The internet of things: A survey," Computer Networks, Vol. 54, No. 15, pp. 2787-2805, 2010.

[17] J. Gubbi, R. Buyya, S. Marusic, and M. Palaniswami, "Internet of things (IoT): A vision, architectural elements, and future directions," Future Generation Computer Systems, Vol. 29, No. 7, pp. 1645-1660, 2013.

[18] D. Bradley, D. Russell, I. Ferguson, J. Isaacs, A. MacLeod, and R. White, "The Internet of things - The future or the end of mechatronics," Mechatronics, Vol. 27, pp. 57-74, 2015.

[19] V. Krotov, "The Internet of things and new business opportunities," Business Horizons, Vol. 60, No. 6, pp. 831-841, 2017/11/01/, 2017.

[20] N. Agarwal, and A. Brem, "Strategic business transformation through technology convergence: implications from General Electrics industrial internet initiative," International Journal of Technology Management, Vol. 67, No. 2/3/4, pp. 196214, 2015.

[21] M. E. Porter, and J. E. Heppelmann, "How smart, connected products are transforming companies," Harvard Business Review, Vol. 93, No. 10, pp. 96-16, 2015.

[22] A. Pal, and K. Kant, "IoT-based sensing and communications infrastructure for the fresh food supply chain," Computer, Vol. 51, No. 2, pp. 76-80, 2018.

[23] M. J. Baucas, and P. Spachos, "A scalable IoT-fog framework for urban sound sensing," Computer Communications, Vol. 153, pp. 302-310, 2020.

[24] M. A. Bouras, A. Ullah, and H. Ning, "Synergy between communication, computing, and caching for smart sensing in internet of things," Procedia computer science, Vol. 147, pp. 504-511, 2019.

[25] M. Ilyas, "Internet of things (iot) and emerging application," Systemics, Cybernetics and Informatics, Vol. 17, No. 5, pp. 27-31, 2019. 
[26] W. H. Weng, and W. T. Lin, "A mobile computing technology foresight study with scenario planning approach," International Journal of Electronic Commerce Studies, Vol. 6, No. 2, pp. 223-232, 2015.

[27] W. H. Weng, and W. T. Lin, "Development assessment and strategy planning in mobile computing industry," in 2014 IEEE International Conference on Management of Innovation and Technology, Singapore, 2014, pp. 453-457.

[28] W. H. Weng, and W. T. Lin, "Development trends and strategy planning in big data industry," Contemporary Management Research, Vol. 10, No. 3, pp. 203214, 2014.

[29] W. H. Weng, and W. T. Lin, "Development assessment and strategy planning in cloud computing industry," International Journal of Electronic Commerce Studies, Vol. 5, No. 2, pp. 257-266, 2014.

[30] W. H. Weng, and W. T. Lin, "A scenario analysis of wearable interface technology foresight," in The International Conference on Electronic Business (ICEB), Taipei, 2014, pp. 8-15.

[31] A. Reyna, C. Martín, J. Chen, E. Soler, and M. Díaz, "On blockchain and its integration with IoT. Challenges and opportunities," Future generation computer systems, Vol. 88, pp. 173-190, 2018.

[32] O. Novo, "Blockchain meets IoT: An architecture for scalable access management in IoT," IEEE Internet of Things Journal, Vol. 5, No. 2, pp. 11841195, 2018.

[33] M. A. Khan, and K. Salah, "IoT security: Review, blockchain solutions, and open challenges," Future Generation Computer Systems, Vol. 82, pp. 395-411, 2018.

[34] S. Huh, S. Cho, and S. Kim, "Managing IoT devices using blockchain platform." pp. 464-467.

[35] A. S. Bharadwaj, "A resource-based perspective on information technology capability and firm performance: an empirical investigation," MIS Quarterly, Vol. 24, No. 1, pp. 169-196, 2000.

[36] R. M. Grant, "Prospering in dynamically-competitive environments: organizational capability as knowledge integration," Organization Science, Vol. 7, No. 4, pp. 375-387, 1996.

[37] M. E. Porter, Competitive strategy, New York: Free Press, 1980.

[38] M. E. Porter, and V. E. Millar, "How information gives you competitive advantage," Harvard Business Review, Vol. 63, No. 4, pp. 61-78, July/August, 1985. 
[39] C. B. Li, and J. J. L. Li, "Achieving superior financial performance in China: Differentiation, cost Leadership, or both?," Journal of International Marketing, Vol. 16, No. 3, pp. 1-22, 2008.

[40] C. V. L. Hill, "Difierentiation versus low cost or differentiation and low cost: A contingency framework," Academy of Management Review, Vol. 13, No. 3, pp. 401-412, 1988.

[41] A. I. Murray, "A contingency view of Porter's "generic strategies"," Academy of Management Review, Vol. 13, No. 3, pp. 390-400, 1988.

[42] M. Haddara, and A. Elragal, "The readiness of erp systems for the factory of the future," Procedia Computer Science, Vol. 64, pp. 721-728, 2015.

[43] N. Benias, and A. P. Markopoulos, "A review on the readiness level and cybersecurity challenges in Industry 4.0." pp. 1-5.

[44] I. Ng, K. Scharf, G. Pogrebna, and R. Maull, "Contextual variety, internet-ofthings and the choice of tailoring over platform: mass customisation strategy in supply chain management," International Journal of Production Economics, Vol. 159, pp. 76-87, 2015.

[45] X. Yu, B. Nguyen, and Y. Chen, "Internet of things capability and alliance," Internet Research, Vol. 26, No. 2, pp. 402-434, 2016, 2016.

[46] M. Taylor, D. Reilly, and C. Wren, "Internet of things support for marketing activities," Journal of Strategic Marketing, Vol. 28, No. 2, pp. 149-160, 2020.

[47] P. A. Pavlou, "Internet of things-will humans be replaced or augmented?," Marketing Intelligence Review, Vol. 10, No. 2, pp. 42-47, 2018.

[48] D.-I. Shin, "An exploratory study of innovation strategies of the internet of things SMEs in South Korea," Asia Pacific Journal of Innovation and Entrepreneurship, Vol. 11, No. 2, pp. 171-189, 2017.

[49] T. Guarda, and M. F. Augusto, "Geographic marketing intelligence: gmi model," in Second International Conference on Applied Informatics (ICAI Workshop), Madrid, Spain, 2019, pp. 205-214.

[50] J. Wu, J. Chen, and W. Dou, "The Internet of things and interaction style: the effect of smart interaction on brand attachment," Journal of Marketing Management, Vol. 33, No. 1-2, pp. 61-75, 2017/01/02, 2017.

[51] F.-Y. Lo, and N. Campos, "Blending Internet-of-things (IoT) solutions into relationship marketing strategies," Technological Forecasting and Social Change, Vol. 137, pp. 10-18, 2018.

[52] S. F. Slater, E. M. Olson, and G. T. M. Hult, "The moderating influence of strategic orientation on the strategy formation capability-performance relationship," Strategic Management Journal, Vol. 27, No. 12, pp. 1221-1231, 2006. 
[53] E. Claver-Cortés, E. M. Pertusa-Ortega, and J. F. Molina-Azorín, "Characteristics of organizational structure relating to hybrid competitive strategy: implications for performance," Journal of Business Research, Vol. 65, No. 7, pp. 993-1002, 2012.

[54] A. McAfee, and E. Brynjolfsson, "Big data - the management revolution," Harvard Business Review, Vol. October, pp. 1-9, 2012.

[55] H. Mintzberg, "Strategy formation in an adhocracy," Administrative Science Quarterly Vol. 30, No. 2, pp. 160-197, 1985.

[56] H. Mintzberg, and J. A. Waters, "Of strategies, deliberate and emergent," Strategic Management Journal, Vol. 6, No. 3, pp. 257-272, 1985.

[57] M. Janssen, H. van der Voort, and A. Wahyudi, "Factors influencing big data decision-making quality," Journal of Business Research, Vol. 70, pp. 338-345, 2017.

[58] S. Akter, S. F. Wamba, A. Gunasekaran, R. Dubey, and S. J. Childe, "How to improve firm performance using big data analytics capability and business strategy alignment?," International Journal of Production Economics, Vol. 182, pp. 113-131, 2016.

[59] K. Xie, Y. Wu, J. Xiao, and Q. Hu, "Value co-creation between firms and customers: the role of big data-based cooperative assets," Information \& Management, Vol. 53, No. 8, pp. 1034-1048, 2016.

[60] C. B. Jarvis, S. B. MacKenzie, and P. M. Podsakoff, "A critical review of construct indicators and measurement model misspecification in marketing and consumer research," Journal of consumer research, Vol. 30, No. 2, pp. 199-218, 2003.

[61] Y. Lu, and K. Ramamurthy, "Understanding the link between information technology capability and organizational agility: an empirical examination," MIS Quarterly, Vol. 35, No. 4, pp. 931-954, 2011.

[62] A. K. Kohli, and B. J. Jaworski, "Market orientation: the construct, research propositions, and managerial implications," Journal of Marketing, Vol. 54, No. 2, pp. 1-18, 1990.

[63] A. K. Kohli, B. J. Jaworski, and A. Kumar, "Markor: a measure of market orientation," Journal of Marketing Research, Vol. 30, No. 4, pp. 467-477, 1993.

[64] J. C. Narver, and S. F. Slater, "The effect of a market orientation on business profitability," Journal of Marketing, Vol. 54, No. 4, pp. 20-35, 1990.

[65] D. W. Vorhies, R. E. Morgan, and C. W. Autry, "Product-market strategy and the marketing capabilities of the firm: impact on market effectiveness and cash flow 
performance," Strategic Management Journal, Vol. 30, No. 12, pp. 1310-1334, 2009.

[66] G. G. Dess, and P. S. Davis, "Porter's (1980) Generic strategies as determinants of strategic group membership and organizational performance," Academy of Management Journal, Vol. 27, No. 3, pp. 467-488, 1984.

[67] M. E. Porter, Competitive advantage, New York: Free Press, 1985.

[68] R. B. Robinson, and J. A. Pearce, "Planned patterns of strategic behavior and their relationship to business- unit performance," Strategic Management Journal, Vol. 9, No. 1, pp. 43-60, 1988.

[69] J.-J. Wu, "Influence of market orientation and strategy on travel industry performance: an empirical study of e-commerce in Taiwan," Tourism Management, Vol. 25, No. 3, pp. 357-365, 2004.

[70] D. Miller, "Relating porter's business strategies to environment and structure: analysis and performance implications," Academy of Management Journal, Vol. 31, No. 2, pp. 280-308, 1988.

[71] D. Miller, "Configurations of strategy and structure: towards a synthesis," Strategic Management Journal, Vol. 7, No. 3, pp. 233-249, 1986.

[72] H. Liu, W. Ke, K. K. Wei, J. Gu, and H. Chen, "The role of institutional pressures and organizational culture in the firm's intention to adopt internet-enabled supply chain management systems," Journal of Operations Management, Vol. 28, No. 5, pp. 372-384, 2010.

[73] H. H. Teo, K. K. Wei, and I. Benbasat, "Predicting intention to adopt interganizaitonal linkages: an institutional perspective " MIS Quarterly, Vol. 27, No. 1, pp. 19-49, 2003.

[74] J. S. Armstron, and T. S. Overton, "Estimating nonresponse bias in mail surveys," JMR, Journal of Marketing Research (pre-1986), Vol. 14, No. 3, pp. 396, Aug 1977, 1977.

[75] C. M. Ringle, S. Wende, and A. Will, SmartPLS 2.0. M3. Hamburg: SmartPLS, 2005.

[76] D. V. Cicchetti, K. Koenig, A. Klin, F. R. Volkmar, R. Paul, and S. Sparrow, "From bayes through marginal utility to effect sizes: a guide to understanding the clinical and statistical significance of the results of autism research findings," $J$ Autism Dev Disord, Vol. 41, No. 2, pp. 168-74, Feb, 2011.

[77] J. C. Nunnally, and I. H. Bernstein, Psychometric theory, 3 ed., New York: McGraw-Hill, 1994.

[78] D. Campbell, T., and D. Fiske, W., "Convergent and discriminant validation by the multitrait-multimethod matrix," Psychological Bulletin, Vol. 56, No. 2, pp. 81-105, 1959. 
[79] J. F. Hair Jr, G. T. M. Hult, C. Ringle, and M. Sarstedt, A primer on partial least squares structural equation modeling (PLS-SEM): Sage publications, 2016.

[80] K. J. Preacher, and A. F. Hayes, "Asymptotic and resampling strategies for assessing and comparing indirect effects in multiple mediator models," Behavior research methods, Vol. 40, No. 3, pp. 879-891, 2008.

[81] B. J. Jaworski, and A. K. Kohli, "Market orientation: antecedents and consequences," Journal of Marketing, Vol. 57, No. 3, pp. 53-70, 1993.

[82] M. Chan, D. Esteve, J. Y. Fourniols, C. Escriba, and E. Campo, "Smart wearable systems: current status and future challenges," Artif Intell Med, Vol. 56, No. 3, pp. 137-56, Nov, 2012.

[83] B. Chen, X. Wang, Y. Huang, K. Wei, and Q. Wang, "A foot-wearable interface for locomotion mode recognition based on discrete contact force distribution," Mechatronics, Vol. 32, pp. 12-21, 2015.

[84] A. Gruebler, V. Berenz, and K. Suzuki, "Emotionally assisted human-robot interaction using a wearable device for reading facial expressions," Advanced Robotics, Vol. 26, No. 10, pp. 1143-1159, 2012.

[85] N. Chung, H. Han, and Y. Joun, "Tourists' intention to visit a destination: the role of augmented reality (AR) application for a heritage site," Computers in Human Behavior, Vol. 50, pp. 588-599, 2015.

[86] S. Meža, Ž. Turk, and M. Dolenc, "Measuring the potential of augmented reality in civil engineering," Advances in Engineering Software, Vol. 90, pp. 1-10, 2015.

[87] N. Petersen, and D. Stricker, "Cognitive augmented reality," Computers \& Graphics, Vol. 53, pp. 82-91, 2015. 